\title{
¿Jueces en la política o políticos en los tribunales? Reflexiones en torno a la judicialización de la política a partir de casos de América Latina
} Judges in politics or politicians in courts? Reflections around the judicialization of politics from cases of Latin America

\author{
Marisa Ramos Rollón \\ Universidad Complutense de Madrid \\ ORCID ID 0000-0001-7541-3529 \\ mlramos@ucm.es
}

\section{Cita recomendada:}

Ramos Rollón, M. (2021). ¿Jueces en la política o políticos en los tribunales? Reflexiones en torno a la judicialización de la política a partir de casos de América Latina. Eunomía. Revista en Cultura de la Legalidad, 20, pp. 86-103.

\section{Resumen}

En este artículo, se analiza el fenómeno de la judicialización de la política, aportando una revisión del concepto y sus expresiones que podría facilitar su contraste empírico. Para ello, se revisa la naturaleza del concepto, sus distintas acepciones y la eventual confusión que genera la asociación del fenómeno a la vertiente sustantiva del proceso judicial más que a la orgánica o funcional. Para avanzar en las posibilidades de la observación empírica, se propone una tipología de expresiones de judicialización de la política que se contrasta, posteriormente, con casos paradigmáticos de América Latina.

\section{Palabras clave}

Judicialización de la política; activismo judicial; democracia representativa; poderes judiciales; América Latina.

\section{Abstract}

In this article, the phenomenon of the judicialization of politics is analyzed, providing a review of the concept and its expressions that could facilitate its empirical contrast. The nature of the concept, its different meanings and the possible confusion generated by the association of the 
phenomenon with the substantive aspect of the judicial process rather than the organic one, that is, the political as matter, are reviewed. To advance the possibilities of empirical observation, a typology of expressions of judicialization of politics is proposed, which is subsequently contrasted with paradigmatic cases in Latin America.

\title{
Keywords
}

Judicialization of politics; judicial activism; representative democracy; judicial powers; politicization of justice; Latin America.

\begin{abstract}
SUMARIO. 1. Introducción: el creciente protagonismo político de los sistemas judiciales. 2. Naturaleza del fenómeno de la judicialización de la política. 2.1. Del «activismo Judicial» a la «judicialización de la política». 2.2. Expresiones de la judicialización de la política. 2.3 Una propuesta de tipología de expresiones de judicialización de la política. 3. Algunas expresiones de la judicialización de la política en América Latina. 4. Conclusión: la judicialización de la política y su impacto en la democracia.
\end{abstract}

\section{Introducción}

Desde hace ya varias décadas, los sistemas judiciales han cobrado un protagonismo creciente en la arena política, adquiriendo un supuesto papel central en la resolución de conflictos sociales y/o políticos o tomando decisiones que generan impactos de envergadura política. De hecho, la centralidad del poder judicial en el contexto político actual crece a medida que decrece la legitimidad del sistema democrático en su conjunto y en las instituciones de representación política en particular, es decir, parlamentos y partidos políticos. También resaltan los tribunales en contextos de transición política y en paralelo a procesos de empoderamiento de la sociedad civil. Además, en este protagonismo ha influido el activo papel y la toma de posición política de los mismos poderes judiciales, ansiosos muchas veces de participar en la contienda política. Finalmente, también esta centralidad de las instituciones judiciales en los sistemas políticos ha ido asociada al hecho de que, en las últimas décadas, muchos Gobiernos, así como cortes supremas con competencias de política pública y de iniciativa legislativa, han promovido reformas judiciales de carácter más o menos integral, buscando resituar el rol, la función y la legitimidad de las instituciones del sector justicia, lo que ha colocado a estas instituciones en el centro de la agenda política y mediática. Estas reformas han sido variadas, respondiendo esa diversidad a la misma complejidad de los sistemas de justicia, a los diferentes fines y objeto de las mismas y, en suma, a los distintos enfoques desde los cuales se han planteado ${ }^{1}$.

\footnotetext{
${ }^{1}$ Las reformas que, desde la premisa de la justicia como servicio público, han promovido modificaciones en torno a la eficacia, la eficiencia y la calidad de la justicia, o introduciendo formas más amigables de acceso a la misma y promoviendo procesos de transparencia y de justicia abierta (lo que se está ya trabajando en países de América Latina a través de la Cumbre Judicial o en el marco de la OEA vía la Ley Interamericana de Acceso a la Información). Las reformas llevadas a cabo desde la premisa de la justicia como regulador de la economía, a través de las cuales se pretenden disminuir los costes de transacción entre los actores económicos, reducir trámites, simplificar procesos y promover acciones que contribuyan a aportar seguridad jurídica al sistema. Finalmente, poniendo el foco en los diseños institucionales y en las interacciones entre poderes, se han llevado a cabo procesos de cambio que han tenido como fin promover una mayor independencia de los poderes judiciales, así como incentivar un mejor ejercicio de responsabilidad política por parte de estas instituciones. En este marco, los cambios se alinean en torno a un eje de tensión entre dos principios clave: la necesaria independencia judicial, por un lado, y la compleja exigencia de responsabilidad política a los jueces, por otro. En definitiva, y sintetizando un debate complejo, se recrea la recurrente tensión entre la idea de separación de poderes frente a la del control entre poderes, a la que hace referencia Ackerman (1999) o Jiménez Asencio (2017), entre muchos otros. Específicamente, y con el fin de proteger y garantizar la independencia judicial, se han diseñado distintos modelos de Gobierno judicial, con diferentes sistemas de acceso y carrera judicial
} 
Esta supuesta centralidad política de los poderes judiciales está siendo interpretada tanto como producto de un fenómeno «normal», resultado del mayor activismo judicial al que desembocan ciertos cambios institucionales o procesos de madurez democrática, como expresión de un fenómeno "patológico», consecuencia de crisis políticas y sociales que afectan a la tradicional división de poderes, al normal funcionamiento del Estado de derecho y, en definitiva, a la misma democracia representativa. En el primer caso, el desarrollo de la justicia constitucional por una parte, y la llegada a los tribunales de casos «excepcionales» de naturaleza política, como pueden ser aquéllos que cuestionan al mismo Estado, al sistema social que el ordenamiento jurídico tiene como función regular o a algunos de sus más altos mandatarios, ponen a las estructuras judiciales en situación que, saliéndose de su papel tradicional (los delitos o, en general, las controversias «comunes»), les obliga a intervenir en "delitos de naturaleza política», asumiendo a veces funciones para las que no fueron creados y/o poniendo en peligro sus propias costuras. En el segundo supuesto, son los propios poderes judiciales los que, por distintas razones, deciden intervenir, haciéndolo de forma nítida en cuestiones de tipo político. Ambos fenómenos, en todo caso, están siendo conceptualizados como fenómenos de judicialización de la política.

A esta judicialización de la política se ha llegado por distintas causas ${ }^{2}$, siendo lugar común referirse a la misma como consecuencia de la crisis de la democracia representativa y de la carencia de canales de resolución de conflictos. A su vez, este desplazamiento de los canales de resolución de conflictos y de los mecanismos de toma de decisiones está impactando, de forma indudable, en el funcionamiento de las democracias.

Este protagonismo de los jueces ha despertado el interés por el estudio de la justicia desde el ámbito politológico, que hasta ese momento había desatendido, en gran medida, el estudio de los sistemas de justicia ${ }^{3}$. El desarrollo de la corriente de análisis de Judicial Politics está, afortunadamente, resituando la temática en la agenda académica e investigadora. Sin embargo, las investigaciones sobre este indeterminado y etéreo proceso, aun siendo cada vez más numerosas, no están avanzando a la misma velocidad que el tratamiento mediático del problema, lo que dificulta el análisis de sus causas e impactos. Además, esta temática requiere una complementariedad de enfoques de análisis para captar adecuadamente los diversos planos del mismo, tanto políticos como jurídicos.

Por ello, se considera necesario avanzar y profundizar en la naturaleza del fenómeno de la judicialización a partir de experiencias latinoamericanas, no solo para diferenciarlo de otros fenómenos con los que pudiera confundirse, sino para identificar

o de separación entre las funciones administrativas y jurisdiccionales, entre otros, modelos que acaban teniendo impactos diferenciados en el fin perseguido (ver Ramos Rollón, 2017).

2 Ferejohn (2002) analizó ya hace algunos años los factores explicativos de la judicialización de la política, apelando a la hipótesis de la fragmentación (la fragmentación del poder limita la capacidad de parlamentos y gobiernos para legislar, abriendo espacios a los poderes judiciales), a la hipótesis de los derechos (los tribunales como defensores de derechos de minorías) o la hipótesis contra mayoritaria (la asociación de los poderes judiciales a los intereses de las minorías frente al rodillo de las mayorías en los parlamentos y Gobiernos). También se han planteado explicaciones vinculadas al diseño institucional y las mayores competencias de los poderes judiciales como consecuencia de las reformas derivadas tanto del avance del constitucionalismo como de las demandas de independencia (Carvalho, 2007).

${ }^{3} \mathrm{Ha}$ sido en los últimos años cuando se ha producido un acercamiento sólido y estable al análisis de los sistemas judiciales desde la ciencia política, especialmente en el ámbito anglosajón, menor en el europeo y aún testimonial desde la ciencia política en España. No deja de ser paradójico este desdén por el estudio de los sistemas de justicia desde la ciencia política, en tanto que las judiciales son instituciones clave, imprescindible para el adecuado análisis de los actuales sistemas políticos. 
las dimensiones del mismo, así como sus expresiones típicas, con el fin de contribuir a avanzar en su investigación y contraste empírico. Este análisis se apoya en la importante contribución de diversos autores que han analizado el papel de los tribunales en la política latinoamericana de las últimas décadas y que han contribuido a comprender las transformaciones generadas en la relación entre poderes y a resituar las funciones de los poderes judiciales y su impacto en la democracia ${ }^{4}$. Este trabajo, sin embargo, aborda un plano no necesariamente cubierto por las investigaciones previas, esto es, la determinación del repertorio de expresiones de la judicialización identificadas a partir de casos actuales, con el fin de delimitar las manifestaciones genuinas de judicialización y aquellas otras que, siendo similares, encajan mejor en otras conceptualizaciones.

Avanzar, por tanto, en estos dos planos es el objeto del presente trabajo. En una primera parte, se abordará la naturaleza del fenómeno, así como algunas de sus expresiones y de las dimensiones que permitirían su medición. A continuación se analizarán algunas de sus expresiones concretas, tomando como referencia casos de América Latina ${ }^{5}$. La hipótesis del trabajo es que algunas expresiones habitualmente vinculadas al concepto de la judicialización se asocian a procesos históricos y son, por tanto, resultado de la maduración de algunos desarrollos institucionales (como la justicia constitucional), muy distintos de aquellos otros vinculados a la extralimitación o perversión de las funciones propias de los poderes judiciales y su utilización o captura con fines políticos.

Con ello se trata de contribuir, desde un enfoque politológico, a la compresión del fenómeno y a su eventual medición. Hay que tomar en consideración que la judicialización de la política puede estar impactando de forma muy contundente en el funcionamiento de las democracias actuales, pero que no está recibiendo suficiente atención en la agenda de investigación politológica, entre otras razones, por las dificultades asociadas a su naturaleza y a su contrastación empírica. Este tipo de análisis es especialmente necesario tomando como fuente de información las realidades y los procesos generados en sistemas judiciales «continentales» (América Latina y España entre otros), muy distintos, en este ámbito, de los «anglosajones» que han inspirado la mayor parte de los análisis teóricos sobre judicialización de la política $^{6}$. Contribuir a mejorar el ajuste del concepto a realidades distintas de aquellas que lo inspiraron puede justificar también el análisis planteado en este trabajo.

\section{Naturaleza del fenómeno de la judicialización de la política}

\subsection{Del «activismo judicial» a la «judicialización de la política»}

Como ya se ha mencionado, la judicialización de la política se ha convertido en un fenómeno recurrente en el debate público, tanto en medios de comunicación como en conversaciones y foros diversos en numerosos países del ámbito occidental. Académicos como Guarnieri y Pederzoli (1999) o Hirschl (2008) hicieron ya referencia, hace algunos años, a este fenómeno como el Gobierno de los jueces o la «juristocracia». Fueron, sin embargo, Tate y Vallinder (1995) quienes acuñaron el término para referirse a algo tan impreciso y etéreo como el aumento de la influencia de los tribunales en asuntos considerados políticos. En términos generales, la judicialización se ha asociado, por ejemplo, a la actuación de los tribunales en casos

\footnotetext{
${ }^{4}$ Ver, entre otros, Ríos Figueroa (2010) o Sieder, Schjolden y Angell (2005).

5 Tomando en cuenta la metodología de estudios de casos, sobre la que han teorizado, entre otros Eckstein (1979) o Flyvbjerg (2006).

${ }^{6}$ Así lo plantea López (2018) al estudiar el caso de la Corte Constitucional colombiana y la política pública minera.
} 
con amplia repercusión política o a hechos en los que están implicados políticos de alto rango; a casos en los que deben actuar de árbitro entre instituciones; a situaciones de revisión de decisiones adoptadas por otros poderes; o a circunstancias de promoción e impulso de políticas públicas a partir del reconocimiento y promoción de derechos resultantes de sus decisiones. En definitiva, la judicialización va asociada a situaciones tan imprecisas y recurrentes en la actualidad como aquellas en las que los jueces adquieren la condición de actores protagonistas, de una forma u otra, de la vida política de un país.

Esta situación se ha equiparado en muchas ocasiones al fenómeno del activismo judicial $^{7}$ (Feoli 2015). El análisis del activismo judicial ha sido realizado, sobre todo, desde el ámbito anglosajón, tomando como referencia las acciones de los jueces o de los poderes judiciales que traspasan su genuina función judicial para actuar como limitadores de los demás poderes del Estado, fundamentalmente a través del control judicial, o que son promotores de decisiones orientadas al reconocimiento de derechos y a la posterior implementación de políticas para protegerlos y garantizarlos. Es, por tanto, un fenómeno muy asociado al desarrollo del "constitucionalismo» y al creciente rol de la justicia constitucional ${ }^{8}$, de acuerdo a los dos modelos, el continental y el anglosajón ${ }^{9}$. El activismo judicial, además, ha sido analizado, generalmente, desde planteamientos críticos, sobre todo de corte conservador (Cross y Lindquist, 2006, p. 1756), entendiendo que el perfil de juez activista $^{10}$ socava las bases del Estado de derecho, en tanto que el modelo de juez autorestringido las refuerza (Brenes, 2012) ${ }^{11}$.

\footnotetext{
${ }^{7}$ El concepto fue introducido por Arthur Schlesinger Jr. en uno de los números de la Revista Fortune de 1947.

${ }^{8}$ La competencia de revisión judicial se inició en Estados Unidos en el siglo pasado y se generalizó en Europa en el siglo XX. Fue Hans Kelsen quien con posterioridad a la I Guerra Mundial (concretamente en 1920 con su obra «¿Quién debe ser el defensor de la Constitución?») impulsó la justicia constitucional en un modelo concentrado (encargando su defensa a un órgano externo al poder judicial, los tribunales constitucionales, a los que se reconoce una naturaleza jurídico-política), frente al modelo difuso norteamericano (1803, caso Marbury vs. Madison) en el que es todo el poder judicial el encargado de la defensa de la Constitución, teniendo como cúpula al Tribunal Supremo. En Europa ya en el período de entreguerras comenzaron a surgir Tribunales constitucionales, primero en Austria, y más tarde en España con el Tribunal de Garantías Constitucionales en la II República. Con posterioridad a la II Guerra Mundial se generalizó este modelo en la mayor parte de los países europeos, de forma que en estos momentos la mayor parte de estos países cuenta con un Tribunal Constitucional. También los países de América Latina se han acogido al sistema europeo de supremacía constitucional de revisión judicial. La ola democratizadora que se desarrolló a partir de 1990 se acompañó de Tribunales específicos de justicia constitucional (Bolivia, Chile, Colombia, Ecuador, Guatemala, Perú y República Dominicana), de salas especializadas con plena competencia en la Corte Suprema (Costa Rica, El Salvador y Venezuela) y de salas especializadas sin plena competencia (Argentina, Brasil, Honduras, México, Nicaragua, Panamá, Paraguay y Uruguay) (Martínez Barahona 2016, 225). Consecuentemente, en estos momentos, existen dos grandes formatos de control constitucional: el concentrado, de inspiración kelseniana, aplicado en Europa, y el abstracto, que se desarrolla en Estados Unidos. Ver Guarnieri y Pederzoli (1999), Ríos Figueroa (2010) o Sieder, Schjolden y Angell (2005), entre otros.

${ }^{9}$ Cada uno de estos modelos tiene diferente impacto en el activismo político, lo que, en combinación con otros elementos institucionales da lugar a diferentes tipologías de control y consecuentemente de activismo judicial y de judicialización de la política.

${ }^{10}$ Brenes $(2012,298)$, apoyándose en Courtis $(2005,60)$ plantea, sin embargo, la ausencia de relación entre actividad/autorestricción del juez y orientación ideológica.

${ }^{11}$ Aunque el constitucionalismo en modelos continentales ha sido analizado de forma intensa desde el derecho constitucional. Ver, al respecto, Atienza (2011), así como la revisión realizada por Marín (2017) vinculando la judicialización y el nuevo constitucionalismo. El trabajo de Ríos Figueroa y otros (2010) constituye una referencia en el análisis de la justicia constitucional latinoamericana. También Nash Rojas (2011) ha analizado las tendencias jurisprudencias de la justicia constitucional latinoamericana y su impacto en el reconocimiento de derechos económicos, sociales y culturales. Por su parte, Sotomayor (2019) analiza la tipología de poderes constitucionales en América Latina y el impacto político de estas
} diferencias. 
En general, el activismo judicial se expresa de dos formas: 1. Cuando el juez o los tribunales controlan a los otros poderes, imponiéndoles sus preferencias (Feoli, 2015, p. 184); 2. Cuando el juez o el poder judicial interviene en decisiones políticas a través, fundamentalmente, del reconocimiento de derechos y de la consecuente implantación de sus decisiones en políticas públicas (Holland, 1991, p. 1), ampliando de esta forma el espectro de los derechos (Epp, 1998, pp. 12-13). Estas dos formas se podrían corresponder con los dos modelos de activismo judicial que plantea Carvalho (2007, p. 1): el Policy-making approach, que supone una expansión de la jurisdicción sobre el policy-making, en tanto que los tribunales intervienen en asuntos políticos, de forma que las decisiones judiciales van también marcando la agenda política; y 2) el Unconstrained courts approach, que afecta a las situaciones en que los tribunales actúan sin ataduras, libres y activos para expandirse y para intervenir en temas relevantes social y políticamente. Un «juez activo» se equipararía, por tanto, también al tipo de juez que Guarnieri y Pederzoli (1999, p. 65) denominaron «político», frente al juez «mero ejecutor de las normas» (o juez «boca de la ley»), guardián o delegado. Un juez activo sería propio de un modelo de sistema judicial en el que los jueces poseen altos niveles de autonomía respecto a las instituciones políticorepresentativas y respecto al propio sistema normativo, encajando más, por ello, con los modelos anglosajones que con los continentales.

El activismo judicial, de acuerdo con esta visión, sería concebido por algunos (López, 2018, p. 176) como expresión de una desviación de la función judicial, o como un exceso de dicha función, asumiendo, por tanto, que la función judicial está «limitada a resolver casos concretos y del derecho en clave positivista». Quizá también se pueda añadir una explicación adicional, de acuerdo a la cual determinados tipos del denominado activismo judicial no son ni producto de la desviación ni consecuencia de la extensión de sus funciones, sino expresión del desarrollo o de la recuperación del normal funcionamiento del poder judicial en un sistema democrático, con el consiguiente control por parte de jueces y tribunales, también, de los hechos desarrollados en las actividades políticas o, en otros términos, de los «actos políticos» y de «gobierno», hechos o actos que antes quedaban fuera del control jurisdiccional.

En general, el activismo judicial se ha considerado una condición necesaria, aunque no suficiente, para la judicialización de la política. Este proceso que, según Ferejohn (2002) se ha ido desarrollando progresivamente en el contexto de las democracias occidentales después de la II Guerra Mundial ha supuesto, en sus palabras, "un desplazamiento de los parlamentos a los tribunales», siendo expresión no solo de procesos de activismo judicial, sino también de debilitamiento de los poderes políticos, que es compensado por los tribunales. Bien es verdad que, de nuevo, esta referencia genérica a los tribunales que plantea Ferejohn (2002) aplica mejor al ámbito anglosajón que al de influencia latina. En Europa y en América Latina las discusiones en este aspecto deben estar referidas, en correspondencia, con los tribunales constitucionales, a los que se les atribuye una naturaleza mixta jurídico/política que es clave a los efectos del análisis sobre la judicialización. En los tribunales latinoamericanos, ese protagonismo político ha tenido como cabeza a las salas de lo constitucional más que a las «cortes supremas» ordinarias.

\subsection{Expresiones de la judicialización de la política}

Plantea también Ferejohn (2002) tres formas esenciales de expresión de la judicialización de la política: 1) Tribunales aptos para limitar y regular a los parlamentos; 2) Tribunales en los que se hacen las políticas y, 3) Tribunales como espacios de regulación de la conducta política. También otros autores han incorporado el activismo judicial (Tate, 1995; o Sieder, Schjolden y Angell, 2005), como ingrediente clave para definir el concepto. 
Otros, sin embargo, consideran que los elementos genuinos del concepto de judicialización están asociados al debilitamiento de las instituciones representativas y a su incapacidad para canalizar intereses y resolver conflictos. Así, Domingo (2016, p. 37) señala que se estará en presencia de una judicialización de la política cuando cada vez más conflictos políticos, sociales o entre el Estado y la sociedad se resuelven en los tribunales; o cuando diversos actores políticos y/o sociales encuentran incentivos en recurrir a los tribunales con el fin de proteger o promover sus intereses, en el sentido planteado por Uprimny (2011, p. 13) cuando lo circunscribe al hecho de que "ciertos asuntos que tradicionalmente habían sido resueltos por el sistema político empiezan a ser decididos por los jueces»; cuando es creciente la presencia «de los procesos judiciales y de los fallos de los tribunales en la vida política y social, y la creciente resolución en los tribunales de los conflictos políticos, sociales o entre el Estado y la sociedad» (Sieder, Schjolden y Angell, 2005, p. 19). También resulta interesante la definición aportada por Nosetto (2018, pp. 150 152) que concibe la judicialización de la política «como el efecto estratégico de la captura de las prácticas políticas», que se expresaría a través de cuatro tipos de acciones: demandas sociales que se canalizan a través de los tribunales; debate político que se resuelve en las cortes o por los jueces; oposición política y control de producción legislativa que protagonizan las cortes constitucionales, y procesos de diseño y ejecución de políticas en los que intervienen los tribunales.

De acuerdo con esta rápida revisión, se podrían identificar al menos tres elementos presentes en los procesos de judicialización de la política: 1. Activismo judicial expresado en la actividad intensa en materia de reconocimiento de derechos y en la adopción de decisiones de contenido político; 2. Conflictos políticos canalizados a través de los tribunales o resueltos por los jueces; 3 . Utilización de los tribunales por parte de ciertos actores políticos y sociales para proteger y/o defender sus intereses. Sin embargo, estos rasgos constituyentes también podrían ser expresión de aquéllos que definen la esencia misma del sistema judicial: por ejemplo, los tribunales se justifican, precisamente, por su ejercicio como poder moderador para pacificar conflictos sociales; los tribunales constitucionales tienen entre sus funciones esenciales la de intervenir en los conflictos políticos como poder moderador; y en cuanto a la intervención de la jurisdicción en el diseño y ejecución de ciertas políticas, ello es consecuencia del sometimiento de la Administración a la jurisdicción. Por tanto, se requiere identificar algún otro elemento que sea genuino y específico de la judicialización de la política.

En general, el concepto de judicialización de la política se ha definido a partir de dos premisas distintas. Por una parte, desde su concepción como expresión de un proceso de activismo excesivo y de expansión de la actuación de los poderes judiciales, se pone el foco en la acción de control de los tribunales sobre los otros poderes, limitando o incidiendo en sus acciones, especialmente las de regulación y las de elaboración de políticas (Ferejohn, 2002; Tate y Vallinder, 1995; Stone Sweet, 2002, entre otros), acciones que son propias de los poderes políticos (parlamentos y Gobiernos). Por otra, a partir de la consideración de la judicialización de la política como un proceso de redistribución de poder entre los diferentes poderes, instituciones o actores, se pone el acento en el mecanismo a través del cual los tribunales asumen poder político por decisión propia o por decisión de otros, en cuyo caso sus funciones son utilizadas o capturadas por otros poderes o para otros fines (Nosetto, 2018; Hirschl, 2008).

El primer enfoque pone el énfasis en lo sustantivo o material del proceso, es decir, en la intervención de los tribunales en materias "políticas» o de gobierno, en tanto que el segundo enfoque acentúa la vertiente orgánica del proceso, es decir, en los tribunales como actores políticos y en su comportamiento como tales. En otros 
términos, no se trata tanto del resultado de la acción judicial, sino del proceso político que determina ese resultado. Por ello, la inclusión del componente del activismo judicial y especialmente la equiparación de la judicialización de la política con la intervención en materias de contenido político (incluyendo los casos de gran corrupción o el reconocimiento de derechos a partir de decisiones de las cortes o salas constitucionales) puede confundir más que aclarar. En el modelo continental, al que pertenecen los sistemas latinoamericanos, la creación de los derechos se lleva a cabo a través de textos declarativos; tema distinto es que sus perfiles o su expansión puedan desarrollarse mediante el dictado de resoluciones por los Tribunales. Sin embargo, esa "definición» de los derechos puede ser, y lo es habitualmente, consecuencia de una tarea "ordinaria» del desarrollo de un modelo de jurisdicción, la constitucional, y por tanto resultado del desarrollo de la justicia constitucional y del proceso de "constitucionalización» de derechos, proceso en el que ha influido también de forma decisiva la maduración de las sociedades civiles y de sus organizaciones sociales, que han ido ampliando su repertorio de estrategias, incluyendo en él también la legal ${ }^{12}$. Por tanto, resulta problemático considerar al activismo judicial elemento esencial para definir la judicialización de la política. Más bien habría que considerarlo un producto del desarrollo del constitucionalismo o una consecuencia de la actividad de los jueces cuando les llegan casos de contenido «político».

\subsection{Una propuesta de tipología de expresiones de judicialización de la política}

Por tanto, en un intento de ceñir la judicialización a sus elementos más genuinos, es decir, a los aspectos relacionados con las transformaciones en cuanto a órgano y función judicial y, por tanto, los referidos tanto a la canalización de conflictos políticos en los tribunales como a la utilización de los mismos con fines políticos, se plantean las concretas expresiones del concepto que podrían servir para acotar sus límites. En los cuatro primeros tipos los jueces o los tribunales se sitúan en una posición pasiva, al menos inicialmente, mientras que en los dos últimos adquieren un rol activo que provoca la judicialización de la política:

1. Ruptura del ordenamiento jurídico como expresión política: una expresión del fenómeno de la judicialización de la política puede hacer referencia a situaciones genuinamente "políticas» que no encuentran su salida en ese ámbito, de forma que sus actores dirimen sus diferencias, sin importar la materia de que se trate, rompiendo el ordenamiento jurídico y realizando actos ilícitos de diversos tipos que obligan a intervenir a los tribunales. En el grupo entrarían las situaciones a las que deben enfrentarse los tribunales ante rupturas del ordenamiento jurídico como intentos de golpe de Estado o las tomas de tierras por parte de grupos de campesinos (como en Honduras, con la invasión de tierras en El Bajo Aguán por parte de campesinos y la paralela militarización y judicialización del conflicto en beneficio de los intereses de grandes multinacionales).

2. Demandas políticas canalizadas a través de la justicia: en otras ocasiones, no se trata tanto de romper el marco constitucional, sino de llevar a cabo actos políticos a través de medios que no son los habituales en «la política», y ello como consecuencia de que esos caminos "políticos» han sido "cerrados» por «la otra parte». Es, entonces, cuando la realización de ciertos actos por esa parte, que no encuentra circuitos propiamente políticos, judicializa el caso, llevando a los jueces a resolver «cuestiones ordinarias» pero politizadas en su génesis, orientación o desarrollo. Formarían parte de este grupo, por ejemplo,

\footnotetext{
12 Ver al respecto Smulovitz (2008) y Ruibal (2015).
} 
los casos de prevaricación en los que están implicados funcionarios o políticos responsables por la falta de acción política o por la toma de decisiones claramente injustas, uno de cuyos muchos ejemplos pueden ser los casos no investigados de delincuencia común, que lleva en muchas ocasiones a una escalada en las reclamaciones ciudadanas que puede terminar desembocando en procesos judiciales claramente politizados por la carga política que conllevan.

3. Utilización de los recursos judiciales: se refiere al uso de las técnicas de control de la constitucionalidad, que han permitido a los partidos en minoría y a la oposición en general obstaculizar, sirviéndose de los tribunales, la entrada en vigor de las leyes. En este caso se produce esa judicialización de la política al convertirse los tribunales en meros instrumentos involuntarios de la política.

4. Utilización de los tribunales para hacer oposición o para hacer política: también hay supuestos de clara utilización de los tribunales para la contienda política, cuando se usa la justicia como mero altavoz político de las controversias partidistas, y los tribunales aceptan jugar ese papel convirtiéndose de esa manera en actor político, tanto para hacer oposición como para hacer política en general. En el caso de la oposición, acudiendo a los tribunales se consiguen los fines sin los costes de la contienda «cuerpo a cuerpo», forma especialmente efectiva en casos de mayorías parlamentarias que actúan como «rodillos» (Tate y Vallinder, 1995). Incluso, aunque los resultados del proceso no sean favorables, puede ser un incentivo suficiente la exposición a los medios que genera el proceso. Pero esta vía puede ser utilizada también por los mismos Gobiernos o por sus grupos políticos afines, aprovechando la ventaja de trasladar a los tribunales la decisión en torno a temas políticos «complejos o sensibles» (Domingo, 2004, pp. 108-111), o derivando hacia ellos las denominadas «patatas calientes» (Hirsch, 2008), es decir, los asuntos que generan divisiones o que son complejos. A través de esta estrategia, se intentan despolitizar ciertos temas, evitar la responsabilidad de la decisión final o salir del "callejón sin salida político» en el que pueden desembocar ciertos temas (Brenes, 2012, p. 299). La utilización de los tribunales para alterar el marco constitucional, como las decisiones de las cortes constitucionales latinoamericanas que han autorizado la reelección de los presidentes, son un ejemplo paradigmático de esta utilización de los tribunales con fines políticos. De igual forma, como parte de la contienda política, se están desarrollando estrategias ofensivas por parte de los actores políticos, utilizando los tribunales para fines políticos en lo que se ha denominado procesos de «lawfare». Especialmente, a propósito de la centralidad del debate en torno a la corrupción política, un mecanismo cada vez más frecuente del repertorio de estrategias políticas y del debate mediático es el de las denuncias por prácticas de corrupción, pivotando la agenda mediática y política en torno a los escándalos de corrupción. En este contexto, los tribunales de justicia se han llenado de casos en los que están implicados gobernantes, funcionarios y referentes políticos, acusados de participar en la comisión de delitos, con mayor o menor sustento jurídico. Estas causas, y sus tiempos, constituyen no solo demandas de justicia, sino también, siguiendo de nuevo a Nosetto (2018), prendas de negociación política, en las que se ven afectados, a favor y en contra, los poderes judiciales que adquieren por ello un inevitable protagonismo político. El caso Odebrecht o el caso Lava Jato son solo los casos más conocidos de este fenómeno.

5. Toma de posición política por parte de los poderes judiciales (o politización de la justicia): bien inducidos por otros actores políticos o bien porque los 
tribunales mismos, excediéndose en su papel, interfieren en decisiones que son genuinamente políticas, y empiezan a jugar como un agente político más, en la que sería, sin duda, la expresión más genuina de la política. Este supuesto se acerca de forma evidente a lo que se ha denominado la politización de la justicia.

6. Resolución de problemas clave del país: hace referencia a aquellos casos en los cuales los poderes judiciales, ante el absentismo de los poderes políticos y administrativos para abordar y resolver problemas claves del país, toman la decisión de intervenir y asumir responsabilidades para evitar crisis de naturaleza diversa (aunque sin salirse, formalmente, de su abstracta competencia). Indicadores de este tipo de judicialización serían la existencia de procesos abiertos en torno a grandes problemas de ámbito social o político (por ejemplo, los casos de gran corrupción en el Perú de Fujimori, de la situación de los Desplazados en Colombia, de la defensa del medio ambiente en Perú a propósito de los problemas derivados de la minería ilegal; los ejemplos son innumerables).

\section{Algunas expresiones de la judicialización de la política en América Latina}

Por tanto, tomando en cuenta las expresiones que genuinamente dan contenido al concepto de judicialización de la política, es posible hacer referencia a algunos ejemplos paradigmáticos en América Latina que pueden contribuir a dar sustancia al fenómeno y a facilitar su análisis empírico. El recuento de casos que podrían servir para ilustrar el fenómeno desborda las posibilidades de este trabajo. Sin embargo, sí hay ejemplos que podrían tener la consideración de casos paradigmáticos, que dan contenido a la idea de judicialización antes planteada.

En cuanto al primer tipo, un posible ejemplo de la ruptura del ordenamiento jurídico como expresión política es el caso del conflicto por la tierra en la zona de El Bajo Aguan (Honduras), que enfrenta desde hace años a más de 300.000 campesinos con algunos grandes propietarios de tierra. Los campesinos de esta región fueron despojados de las tierras que habían trabajado durante décadas gracias a los procesos de reforma agraria promovidos por el Estado de Honduras en la década de 1970, procesos que facilitaron el acceso a la tierra a los campesinos de la zona. Sin embargo, en la década de 1990, sobre todo a partir de la aprobación de la Ley de Modernización y Desarrollo del Sector Agrícola de 1992, se facilitó un proceso de concentración de la tierra en manos de unos pocos y grandes propietarios, incluyendo algunas empresas extranjeras, que orientaron la tierra fundamentalmente al cultivo de palma. Este proceso supuso una pérdida de los derechos de propiedad de los pequeños campesinos y de las cooperativas que habían creado. A través de manejos irregulares y fraudes de ley, se les otorgó a los grandes propietarios la posibilidad de extenderse más allá de sus límites, realizándose traspasos de propiedad al margen de los marcos jurídicos existentes. A raíz de esta situación, los campesinos iniciaron procesos judiciales orientados a recuperar la titularidad de las tierras (OMCT-FIDH 2016, p. 29) procesos que, sin embargo, no tuvieron ningún impacto. A partir de 2010, el gobierno alcanzó un acuerdo con los movimientos campesinos, consistente en la compra por parte del Estado de tierras para entregar a los campesinos. Sin embargo, este acuerdo apenas se ha cumplido. En contrapartida, han recibido hostigamientos, amenazas y han sido asesinados representantes del movimiento campesino y defensores de derechos humanos, tal como ha recogido la Comisión Interamericana de Derechos Humanos (CIDH) (2015). Además, hay que destacar también el hostigamiento judicial en contra de estos defensores. Según la información de la CIDH, hasta octubre de 2014, 27 líderes campesinos habrían sido procesados por diversos delitos tales como usurpación de tierra, daño al medio ambiente y a la 
propiedad privada (CIDH, 2015, p. 78) $)^{13}$. Por tanto, la ausencia de soluciones políticas y jurídicas al conflicto de la tierra y a la usurpación de tierras a los campesinos ${ }^{14}$, no solo ha provocado la utilización de procedimientos de ruptura del ordenamiento jurídico (la toma de tierras) por parte de los movimientos campesinos, sino también respuestas de hostigamiento judicial además de secuestros, amenazas y asesinatos de los campesinos y de sus defensores. Los procesos judiciales en torno a estos conflictos están, por tanto, en origen y desarrollo claramente politizados, instrumentalizados como parte del repertorio de acciones que está llevando a cabo el sector más poderoso del conflicto ${ }^{15}$.

Un ejemplo del segundo tipo de judicialización, la relativa a la utilización de la justicia para canalizar demandas que no encuentran solución por la vía política, podría ser el caso de los 43 de Ayotzinapa (México) y la cuestión específica relativa a la obstrucción de la justicia por parte del Gobierno de Peña Nieto. En septiembre de 2014, 43 estudiantes de la Escuela Normal de Iguala desaparecieron, después de ser detenidos por la policía acusados de tomar ilegalmente un autobús. A la gravedad de la desaparición de los 43 jóvenes se sumó el intento del Gobierno de Peña Nieto y de la Procuraduría General de la República por ocultar los hechos ${ }^{16}$ y por obstaculizar las investigaciones. Así lo han ratificado informes independientes de la $\mathrm{CIDH}$ (2016) y de Naciones Unidas (2018). Este último informe acusó al gobierno de Peña Nieto de construir evidencias falsas y de torturar a muchos de los detenidos para que confesaran su participación en el crimen, poniendo el foco en la participación, como actores de la masacre, en un grupo de crimen organizado local, Guerreros Unidos (Sáez, 2019, 25 de septiembre). Por tanto, la impunidad y la corrupción de quienes tendrían que haberse ocupado de investigar y facilitar el proceso judicial del caso explican que, cinco años después, el crimen siga impune. Más aun, se han denunciado importantes irregularidades procesales en los casos judiciales en marcha, de forma que han tenido que ser liberados 77 de los 142 imputados y la mayoría de los implicados aún en prisión probablemente también tendrán que ser liberados (Wola, 2017). Ante esta situación, y para atender a las demandas de justicia por parte de las familias de las víctimas, el actual gobierno de López Obrador ha promovido la creación de una Comisión de la Verdad. El caso judicial de Ayotzinapa será, en todo caso, y sea cual sea su recorrido, ya un caso político.

En lo que se refiere al tercer tipo de judicialización, existen numerosos ejemplos de utilización de los recursos jurídicos y judiciales para llevar a cabo las actividades políticas, tanto por parte de la oposición como incluso por parte de los Gobiernos. Un caso que ilustra bien el uso que hace la oposición política del control constitucional es el brasileño, de forma que el 34,3\% de las Acciones Directas de Inconstitucionalidad entre 1988 y 2002 fueron promovidas por los partidos de oposición (Carvalho 2007, 6). También Nosetto (2018) recuerda el caso argentino en el que, siguiendo el modelo norteamericano de control de constitucionalidad, la oposición ha utilizado la vía del recurso de constitucionalidad como senda privilegiada para vetar las leyes aprobadas por el Congreso:

concretamente, en varios casos resonantes, cuando los legisladores que se oponen a un proyecto de ley no logran frustrar su trámite parlamentario, recurren a los tribunales de justicia, denunciando su inconstitucionalidad. Esta práctica da lugar en muchos

\footnotetext{
${ }^{13}$ Véase también: Informe de Observación Judicial (2016).

14 Sobre la ausencia de intervención política en el conflicto, ver: Proceso Digital (2010, 15 de noviembre) y El Heraldo (2014, 7 de abril).

${ }^{15}$ Ver al respecto el amplio trabajo de investigación de InsightCrime (2016).

${ }^{16}$ En cuyo seno se creó el Grupo Internacional de Expertos Independientes para brindar asistencia técnica al gobierno en la investigación. Ver: https://www.oas.org/es/cidh/actividades/giei/ $\underline{\text { ResumenEjecutivo-GIEl.pdf }}$
} 
casos a medidas cautelares que se prorrogan indefinidamente sin resolver sobre el fondo de la cuestión, impidiendo la puesta en vigencia de la normativa emanada del poder legislativo. De este modo, se produce una novedosa judicialización del proceso legislativo, producto muchas veces de expresiones políticas minoritarias o intensas, que prefieren ejercer el poder de veto ofrecido por instancias judiciales a entrar en las negociaciones que implica la actividad parlamentaria (Nosetto, 2018, p. 150) ${ }^{17}$.

En cuanto al cuarto tipo de judicialización, en América Latina la politización de la justicia es un rasgo endémico que, en los últimos años ha adoptado, simplemente, nuevos bríos. Hay muchos ejemplos de Tribunales que intervienen (y toman partido) en asuntos de alto calado político o de relevancia político-electoral, por su propia decisión o instrumentalizados por otros actores. El caso que ha afectado a Lula en Brasil o la intervención de las cortes supremas en los procesos de reelecciones presidenciales son algunos ejemplos representativos de este tipo de judicialización.

Un claro ejemplo de judicialización se refiere al proceso judicial que todavía tiene abierto el ex presidente Lula Da Silva en Brasil. De hecho, la vida política de Lula da Silva de los últimos 10 años ha estado marcada por decisiones judiciales. Lula Da Silva fue inicialmente implicado en el caso de corrupción de Petrobras (Amaya, 2016, 4 de marzo; Seco, 2016, 5 de marzo) y 11 días después de su detención, fue nombrado Ministro de la Casa Civil por el Gobierno de Dilma Rousseff, lo que fue interpretado por la oposición como un acto tendente a conseguir la inmunidad judicial. Este nombramiento fue suspendido por un Juez del Supremo Tribunal Federal de Brasil, pero un juzgado de Rio de Janeiro levantó la medida cautelar que impedía su nombramiento. Pero ese mismo día, el Juez del Tribunal Supremo, Gilmar Mendes, suspendió de nuevo la medida. En julio de 2017 Lula da Silva fue condenado en primera instancia a nueve años y seis meses de prisión por el Juez Sergio Moro (que posteriormente fue nombrado Ministro de Justicia en el Gobierno de Bolsonaro), siendo la primera vez en la historia que un ex Presidente de Brasil es condenado por corrupción pasiva. Estuvo en prisión desde abril de 2018 hasta noviembre de 2019 en que se ordenó su liberación. El 9 de junio de 2019 se conoció, a través de un extenso reportaje de The Intercept, la filtración de documentos, conversaciones e intercambio de opiniones entre el exjuez de Lava Jato y el actual ministro de Justicia, Sergio Moro, que revelaban la existencia de una coordinación entre Moro y algunos fiscales para encarcelar a Lula Da Silva por la operación Lava Jato (Greenwald y Pougy, 2019, 9 de junio). Por tanto, más allá de los aspectos sustantivos vinculados a estos casos, es evidente que los tribunales y los procesos judiciales han sido utilizados con fines políticos, siendo un hecho, además, el protagonismo de los jueces en el devenir político de Brasil de la última década.

También resulta ejemplo paradigmático de este tipo de judicialización la intervención de las cortes constitucionales o de las salas constitucionales en los procesos de reelección presidencial. Numerosos casos en las últimas décadas ilustran perfectamente este tipo de judicialización de la política y específicamente de la toma de posición de los tribunales en materias políticas. Como es conocido, a finales de la década de 1980, y con el fin de evitar situaciones cercanas a los regímenes autoritarios apenas superados, se llevaron a cabo una serie de cambios constitucionales prohibiendo la reelección de los presidentes de la república. Sin embargo, tan solo unos años después, la ambición de poder y su vocación de perpetuarse en el cargo, llevó a varios presidentes a iniciar procesos de contrarreforma constitucional, empezando por Perú y Argentina. De hecho,

\footnotetext{
17 Como es sabido, también este instrumento se utilizó en España al inicio de la etapa democrática, cuando el PP se dedicó precisamente a la utilización intensiva del «recurso previo de inconstitucionalidad» como forma de hacer política. Este abuso obligó a modificar la LO del Tribunal Constitucional, eliminando este mecanismo.
} 
actualmente sólo México, Paraguay y Guatemala la prohíben totalmente ${ }^{18}$. Un caso extremo en este grupo lo protagonizó el actual presidente de Honduras, Juan Orlando Hernández, que, imitando lo que hicieron otros mandatarios en distintos países para alcanzar el mismo objetivo, provocó una declaración de inconstitucionalidad de la norma constitucional que prohibía la reelección, con una interpretación, en claro fraude de ley, que remite a la Convención Americana de Derechos Humanos. La Corte Suprema mantuvo que las cláusulas que prohibían la reelección presidencial estaban en conflicto con la libertad de expresión y conciencia y limitaban indebidamente la participación política y el debate ${ }^{19}$, y con su fallo permitió que el presidente se presentará a la reelección en 2017, provocando la fractura del país, denuncias de fraude electoral, fuertes desórdenes públicos, intervención de las tropas, muertos y acusaciones de traición constitucional ${ }^{20}$.

También en Bolivia, el presidente Morales fue elegido por primera vez en 2005 de acuerdo con el régimen constitucional anterior. En 2009 se aprobó una nueva Constitución según la cual se estableció el mandato presidencial de cinco años, permitiéndose una sola reelección consecutiva. El presidente Morales fue reelegido en 2009 y 2014. Sin embargo, pretendió modificar el límite de la reelección, para lo que se planteó un referéndum en 2016 que permitiera al presidente y al vicepresidente contender para un tercer periodo consecutivo. El referéndum se perdió, a pesar de lo cual, en una resolución en 2017, el Tribunal Constitucional declaró esta limitación inaplicable, apelando a la Convención Interamericana de Derechos Humanos y al derecho de todo ciudadano a elegir y ser electo.

En lo que se refiere al quinto tipo, el caso abierto en el que está implicada la ex fiscal de Guatemala, Thelma Aldana, es paradigmático de la judicialización de la política como expresión de la toma de posición de los propios tribunales, inducidos por actores políticos y en connivencia con ellos. Durante su gestión como fiscal general y jefa del Ministerio Público, junto al comisionado de la Comisión Internacional contra la Impunidad en Guatemala ( $\mathrm{CICIG}$ ), Iván Velásquez Gómez, Aldana lideró varias investigaciones de alto calado político en las que estaban implicados altos representantes del Gobierno. Entre ellas se encuentra el caso de «La Línea» que acabó con la renuncia y arresto del presidente Otto Pérez Molina y de la vicepresidenta Roxana Baldetti, entre otros altos cargos de ese Gobierno, u otros casos que involucraron a los ex presidentes Álvaro Colom, Álvaro Arzú y Jimmy Morales, como son los de Redes, Corrupción en SAT, Contenedores Puerto Quetzal, Cooptación del Estado y El Bodegón, entre otros. Posteriormente, en 2018, se postuló como candidata a la Presidencia de la República, siendo proclamada como candidata del Movimiento Semilla en enero de 2019. Sin embargo, Aldana no pudo iniciar su campaña debido a que no había recibido aún las credenciales del Tribunal Supremo Electoral. Apenas dos meses después, el juez Víctor Manuel Cruz Rivera ${ }^{21}$ emitió una orden de captura en contra de la candidata Thelma Aldana (Monzón, 2019, 18 de marzo), a pesar de que ese mismo día fue inscrita como candidata presidencial por el Tribunal Supremo Electoral, situación que le brindaba inmunidad de conformidad con la Ley Electoral y de Partidos Políticos y que tendría que haber dejado sin efecto la orden de captura. La Corte de Constitucionalidad, sin embargo, rechazó el amparo

\footnotetext{
${ }^{18}$ La cuestión ha acabado en algún esperpento cuando las parejas -esposos, esposas- de presidentes en el cargo se han presentado a las elecciones para poder burlar limitaciones en la reelección -el caso de la mujer de Álvaro Colom fue especialmente patético-.

${ }^{19}$ Ver al respecto el informe de la Comisión Europea para la Democracia a través del Derecho (Comisión de Venecia) (2018), así como Martínez-Barahona (2010) o Cárdenas y Corredor (2018). Desde un enfoque más crítico acerca de la utilización de la justicia constitucional, ver Viciano y Moreno (2018). ${ }^{20}$ Ver Álvarez y otros (2019).

${ }^{21}$ El juez Víctor Cruz Rivera ha sido cuestionado por sus resoluciones polémicas emitidas en otros casos. Ver: Gramajo (2019, 19 de marzo).
} 
que solicitaba inscribir a Aldana como candidata presidencial, de forma que, como resultado de esta resolución, Thelma Aldana quedó fuera del proceso electoral, que ganó el candidato oficialista Giamattei (Hernández, 2019, 15 de mayo). Esta resolución de la Corte Constitucional constituye un buen ejemplo de toma de posición política de este Tribunal incidiendo de forma directa en la dinámica política del país. Recientemente, Aldana ha recibido asilo político en Estados Unidos (Nómada, 2020, 24 de febrero).

Finalmente, en lo que se refiere al sexto tipo de judicialización, de intervención de los Tribunales en asuntos complejos para abordar una problemática de enorme gravedad que no es abordada por los poderes políticos (Legislativo y Gobierno) un ejemplo representativo lo constituye la intervención de la Corte Constitucional de Colombia en el caso de los Desplazados, en lo que constituye el fallo más ambicioso de sus casi dos décadas de existencia: la Sentencia T-025 de 2004. En ella se menciona que la dramática situación de los más de tres millones de personas desplazadas por la violencia constituía un «estado de cosas inconstitucional». A través de esta figura, se estableció la existencia de una violación masiva y reiterada de los derechos humanos de la población desplazada, situación agravada por problemas estructurales y por políticas públicas ineficaces o inexistentes. De acuerdo con esta sentencia, el Estado colombiano se vio obligado a adoptar una serie de políticas orientadas a cumplir lo establecido en la resolución judicial ${ }^{22}$.

Esta sentencia fue innovadora en tanto reconoció a los desplazados como víctimas centrales del conflicto, en tanto hasta ese momento se habían considerado solo un efecto secundario del mismo. Señalan Saravia y Rodríguez (2015) cuatro características de esta sentencia que la hacen especialmente valiosa no solo para Colombia sino para toda la protección y garantía de derechos humanos. En primer lugar, por el alcance de la sentencia, particularmente amplio, ya que afecta a un número muy importante de población víctima de violaciones de derechos especialmente graves y a un número de actores estatales y sociales también muy importante. De esta forma, la sentencia no sólo protegió a los que habían acudido a la jurisdicción sino a todos los desplazados, que según Internal Displacement Monitoring Center ascendían en 2013 a cinco millones de personas. En segundo lugar, la sentencia 025 es quizá el intento judicial más explícito y sistemático para asegurar la ejecución de una macro sentencia, generando durante seis años 84 decisiones de seguimiento (autos) y 14 audiencias públicas de discusión y balance de las tareas del Gobierno. Un tercer elemento valioso se refiere a la forma de las órdenes dictadas por la Corte que, sin fijar detalles, estableció procedimientos de adopción de políticas en los que se viera implicada también la sociedad civil, generando un proceso participativo y gradual sumamente novedoso. Finalmente, la sentencia es un ejemplo paradigmático de una jurisprudencia por parte de la Corte Constitucional colombiana que se ha convertido ya en referente en jurisprudencia constitucional y protección de derechos ${ }^{23}$.

\section{Conclusión: la judicialización de la política y su impacto en la democracia}

Que los sistemas judiciales han adquirido un protagonismo político que trasciende las funciones genuinas que histórica e institucionalmente tiene asignadas, es una premisa que no genera excesiva controversia. Aun así, uno de los mayores retos para las ciencias políticas y jurídicas es determinar dónde se sitúan los límites entre la política y la justicia y que tipo de interacciones entre ambos planos forman parte de los normales procesos, coyunturales e históricos, de intervención de los tribunales en

\footnotetext{
${ }^{22}$ Al respecto, ver el análisis completo realizado por Rodríguez y Rodríguez (2010).
}

${ }^{23}$ Ver Saravia y Rodríguez (2015), Saravia (2016) y Malagón (2016), entre otros. 
la resolución de conflictos políticos (especialmente de la justicia constitucional) y cuales son expresión de una cierta perversión de esos límites, que es lo que se denominaría como judicialización de la política. Por tanto, el primer reto que hay que seguir confrontando es la identificación de dimensiones que permitan delimitar el concepto y distinguir entre la «normal» judicialización y la extraordinaria.

De hecho, en la revisión conceptual en torno a la judicialización, la utilización de análisis basados en el ámbito anglosajón complica su aplicación a las referencias latinoamericanas. La equiparación de la judicialización de la política a la de contextos marcados por dosis excesivas de activismo judicial desarrollado fundamentalmente por las cortes constitucionales o por las salas constitucionales de las cortes supremas en América Latina, resulta inadecuada por cuanto confunde el desarrollo del constitucionalismo y la «normal» actuación de los jueces y tribunales en el reconocimiento de derechos con situaciones excepcionales de intervención política de los tribunales. Es cierto que en América Latina el desarrollo del constitucionalismo ha presentado rasgos muy peculiares en algunos países, pero esta situación no debe ser problematizada en términos de judicialización. Más bien habría que concluir que la judicialización de la política no va vinculada a la materia (política) que entra en los tribunales, sino al abordaje, por parte de los mismos, de conflictos que se concreta en particulares ilícitos, pero que pertenecen en términos generales y no particulares, al ámbito de lo político. Por tanto, un adecuado abordaje del fenómeno de la judicialización requeriría profundizar más en los procesos políticos asociados a la intervención de jueces y tribunales en conflictos políticos, a la captura de estas instituciones por grupos políticos o de poder y a la utilización de las mismas como espacios de contienda política. Serían, por tanto, estas expresiones las que dan contenido genuino a la judicialización de la política. Por el contrario, asociar la judicialización a la intervención de jueces y tribunales en asuntos de contenido político derivados de la ampliación en el reconocimiento de derechos o de la llegada a los tribunales de casos en los que están implicados altos mandatarios o asuntos de alto calado mediático-político confunde más que aclara, en tanto éstos serían, más bien, expresiones del normal funcionamiento del Estado de derecho en contextos democráticos y de desarrollo constitucional maduros.

De acuerdo con ello, y tomando en cuenta los supuestos genuinos de la judicialización, es decir, la participación de los poderes judiciales en conflictos de tipo político (más allá de los casos específicos que lo motiven), se plantea una propuesta de tipología de situaciones de judicialización que pretende contribuir a precisar mejor este concepto. La aplicación de esta tipología a diversos ejemplos en América Latina pretende explorar los matices del concepto en contextos de aquellos que lo inspiraron. El incipiente contraste de esta tipología con la realidad latinoamericana ha puesto de manifiesto la recurrencia de situaciones basadas en el tipo de judicialización genuina según este trabajo, es decir, la asociada a la toma de posición política de los tribunales y a la instrumentalización de jueces y tribunales con fines políticos. De ello se infiere que la expresión más frecuente de judicialización de la política en América Latina es la relativa a la politización de la justicia, es decir, a la contaminación política del espacio judicial.

Este trabajo también pone de manifiesto la pertinencia de continuar avanzando en el análisis del fenómeno desde diferentes prismas teóricos y metodológicos, así como la oportunidad de su contraste empírico, especialmente en contextos lejanos a los que inspiraron el concepto, con el fin de conectar mejor el debate mediático existente sobre el tema con la evidencia científica necesaria para consolidarlo. 
Bibliografía

Ackerman, B., y Alonso, G. (1999). La política del diálogo liberal. Barcelona, España: Gedisa.

Amaya, L. A. (2016, 4 de marzo). Escándalo Petrobras deja cercado a Lula da Silva. El Tiempo. Recuperado de: https://www.eltiempo.com/archivo/documento/CMS$\underline{16528353}$

Álvarez García, F.J. y otros (2019). El control de la corrupción en América Latina: agenda política, judicialización e internacionalización de la lucha contra la corrupción. Documentos de trabajo - Fundación Carolina: Segunda época (11), pp. 1-31.

Atienza, M. (2011). Dos versiones del constitucionalismo. DOXA: Cuadernos de Filosofía del Derecho (34), pp. 73-88.

Brenes, L. (2012). Judicial Politics y Tribunales electorales. Revista Justicia Electoral, 1 (10), pp. 293-316.

Cárdenas, E. y Corredor, F. (2018). El juez constitucional y la reelección presidencial en América Latina. Revista de Economía Institucional, 20 (38), pp. 45-70.

Carvalho, E. (2007). La judicialización de la política en perspectiva comparada: Brasil, España y Portugal. Ponencia presentada en VIII Congreso Español de Ciencia Política y de la Administración Política para un mundo en cambio. Valencia, España.

Comisión Europea para la Democracia a través del Derecho (Comisión de Venecia) (2018). Informe sobre los límites a la reelección parte I-presidentes. Aprobado por la Comisión de Venecia en su 114a Sesión Plenaria. Estrasburgo, Francia. Recuperado https://www.venice.coe.int/webforms/documents/default.aspx?pdffile=CDL$\mathrm{AD}(2018) 010-\mathrm{spa}$

Comisión Interamericana de Derechos Humanos (2015). Situación de los Derechos Humanos en Honduras. Organización de Estados Americanos.

Courtis, C. (2005). Breves apuntes de caracterización de la actividad política de los tribunales. En F., Ojesto; J, Orozco Henríquez y R ., Vásquez. (Coords.). Jueces y Política (pp. 5984). Ciudad de México: México: Editorial Porrúa.

Cross, F. B., y Lindquist S. A. (2006). The scientific study of judicial activism. Minnesotta Law Review (91), pp. 1752-1783.

Domingo, P. (2004). Judicialization of politics or politicization of the judiciary? Recent trends in Latin America. Democratization, 11(1), pp. 104-126.

Domingo, P. (2016). Rule of law, politics and development: the politics of rule of law reform. London, United Kingdom: Overseas Development Institute. Recuperado de: https://www.odi.org/sites/odi.org.uk/files/resource-documents/10420.pdf

Eckstein, H. (1979). On the" Science" of the State. Daedalus, pp. 1-20.

El Heraldo (2014, 7 de abril). El periodismo necesita inversión. Para compartir esta nota utiliza los íconos que aparecen en la página. El Heraldo. Recuperado de: https://www.elheraldo.hn/pais/569925-214/masivas-invasiones-de-tierras-enhonduras

Epp, C. (1998). The rights revolution. Lawyers, activists, and supreme courts in comparative perspective. Chicago, Estados Unidos: University of Chicago Press.

Feoli, M. (2015). El nuevo protagonismo de los jueces: una propuesta para el análisis del activismo judicial. Revista de Derecho 22 (2), pp. 173-198.

Feoli, M. (2016). Judicialización de la política y activismo judicial: una aproximación a América Latina. Revista Latinoamericana de Derechos Humanos, 27 (1), pp. 7598(24).

Ferejohn, J. (2002). Judicialización de la política, politización de la ley. Revista Mexicana de Ciencias Políticas y Sociales 45 (184), pp. 13-49. 
Flyvbjerg, B. (2006). Five misunderstandings about case-study research. Qualitative inquiry 12.2, pp. 219-245.

Gramajo, J. (2019, 19 de marzo). Otros casos polémicos del juez que ordenó la captura de Aldana. Soy 502. Recuperado de: https://www.soy502.com larticulo/juez-emitio-orden-captura-contra-thelma-aldana-100931

Greenwald, G. y Pougy, V. (2019, 9 de junio). Hidden plot. The Intercept. Recuperado de: $\quad$ https://theintercept.com/2019/06/09/brazil-car-wash-prosecutors-workersparty-lula/

Guarnieri, C. y Pederzoli, P. (1999). Los jueces y la política: Poder Judicial y democracia. Madrid, España: Taurus.

Hernández, M. (2019, 15 de mayo). CC dice "no" a inscripción de Thelma Aldana. Prensa Libre. Recuperado de: https://www.prensalibre.com/guatemala /politica/cc-dice-no-a-inscripcion-de-thelma-aldana/

Hirschl, R. (2008). The judicialization of mega-politics and the rise of political courts. Annual Review Politica Science, 11, pp. 93-118.

Holland, K. (1991). Judicial activism in comparative perspective. Nueva York, Estados Unidos: St. Martin Press.

Informe de Observación Judicial (2016). Honduras: criminalización en el Bajo Aguán: Justicia a Medias.

InsightCrime (2016). Élites y crimen organizado en Honduras: Los Cachiros. InsightCrime. Recuperado de: https://es.insightcrime.org/investigaciones/elitescrimen-organizado-honduras-los-cachiros/

Jiménez A. R. (2017). Jueces, Política y Separación de Poderes. Agenda Pública. Recuperado de: http://agendapublica.elpais.com/jueces-politica-separacionpoderes/.

López, H. (2018). Separación de poderes, políticas públicas y activismo judicial: una discusión a partir de jurisprudencia de la Corte Constitucional colombiana sobre una política pública. Doxa. Cuadernos de Filosofía del Derecho 41, pp. 171-192.

Malagón, L. (2016). La reivindicación de derechos y garantías de los movimientos sociales (LGTBI - Desplazados) a través del activismo y progresismo de la Corte Constitucional colombiana. Diálogo de saberes, 45 (2), pp. 145-162.

Marín, M. L. (2017). Sobre la judicialización de la política: una aproximación desde el neo constitucionalismo. Astrolabio. Revista Internacional de Filosofía (20), pp. 123-135

Martínez Barahona, E. (2010). Las Cortes Supremas como mecanismo de distribución de poder: el caso de la reelección presidencial en Costa Rica y Nicaragua. Revista de Ciencia Política, 30 (3), pp. 723-750.

Martínez Barahona, E. (2016). El Poder Judicial en un sistema político democrático. En: M. Barreda y L. Ruiz (Eds), Análisis de la política: enfoques y herramientas de la ciencia política (pp. 221-238). Madrid, España: Huygens Eds.

Monzón, K. (2019, 18 de marzo). Caso contra Thelma Aldana queda bajo reserva judicial. Presa Libre. Recuperado de: https://www.prensalibre.com/guatemala /justicia/caso-contra-thelma-aldana-queda-bajo-reserva-judicial/

Naciones Unidas (2018). Double injustice. Report on Human Rights Violations in the Investigation of the Ayotzinapa Case. Office of the United Nations High Commissioner for Human Rights.

Nash Rojas, C. (2011). Los derechos económicos, sociales y culturales y la justicia constitucional latinoamericana: tendencias jurisprudenciales. Estudios constitucionales, 9 (1), pp. 65-118.

Nómada (2020, 24 de febrero). Entrevista: Thelma Aldana, la tristeza, la preocupación y el optimismo. Nómada. Recuperado de: https://nomada.gt/pais/actualidad lentrevista-thelma-aldana-la-tristeza-la-preocupacion-y-el-optimismo/

Nosetto, L. (2018). Legitimidad democrática y judicialización de la política: el caso de la Argentina contemporánea. Ius Fugit. Revista de Cultura Jurídica, 21, pp. 145167. 
Proceso Digital (2010, 15 de noviembre). Se reaviva conflicto en el Bajo Aguán y Gobierno ordena militarizar la zona. Proceso Digital. Recuperado de: https://proceso.hn/se-reaviva-conflicto-en-el-bajo-aguan-y-gobierno-ordenamilitarizar-la-zona/

OMCT-FIDH (2016). Honduras, los defensores y defensoras de derechos humanos entre la espada y la pared. Observatorio para la Protección de los Defensores de Derechos Humanos. Recuperado de: https://www.omct.org/files/2016/ 12/24084/honduras informe de mision.pdf

Ramos Rollón, M. (2017). La efectividad de las políticas de justicia de la última década en América Latina. Revista del CLAD Reforma y Democracia, (68), pp. 5-42.

Ríos Figueroa, J. y otros (2010). Justicia constitucional y derechos humanos en América Latina. Revista Latinoamericana de Política Comparada (3), pp. 53-68.

Rodríguez Garavito, C. y Rodríguez Franco, D. (2010). Un giro en los estudios sobre derechos sociales: el impacto de los fallos judiciales y el caso del desplazamiento forzado en Colombia. En: C. Courtis y R. Avila (Eds.), La protección judicial de los derechos sociales (pp. 321-375) Bogotá, Colombia: Dejusticia.

Ruibal, A. M. (2015). Movilización y contra-movilización legal. Propuesta para su análisis. América Latina. Política y Gobierno, 22 (1), pp. 175-198, XXII (1)1.

Sáez, A. (2019). Cinco años de impunidad por la desaparición de los 43 estudiantes de Ayotzinapa. Periódico Internacional. Recuperado de: https://www.elperiodico.com/es/internacional/20190925/cinco-anos-de-bloqueojudicial-para-ayotzinapa-7649096

Saravia, J. y Rodríguez, A. (2015). Los desplazados forzados internos en el estado de cosas inconstitucional, un asunto pendiente. Prolegómenos. Derechos y Valores 18.35, pp. 121-134.

Saravia J. (2016) El papel de la Corte Constitucional Colombiana ante la asistencia estatal a los desplazamientos internos forzados por la violencia. Tesis Doctorado. Universidad del País Vasco, 345 pp.

Seco, R. (2016, 5 de marzo). La fiscalía de Brasil acusa a Lula de enriquecerse con la corrupción. El País. Recuperado de: https://elpais.com/internacional /2016/03/04/actualidad/1457085729 531863.html

Sieder, R., Schjolden, L. and Angell, A. (2005). The judicialization of politics in Latin America. Nueva York, Estadps Unidos: Palgrave Macmillan.

Smulovitz, C. (2008). La política por otros medios. Judicialización y movilización legal en la Argentina. Desarrollo Económico, 48 (190/191), pp. 287-305.

Sotomayor, M. P. (2019). El poder constitucional en América Latina: hacia una tipología de las Cortes Constitucionales de la región. Revista OPERA, 24, pp. 526.

Stone Sweet, A. (2002). Constitutional Politics in France and Germany. Law, Politics, and Judicialization, 82, pp. 184-201.

Tate, C. N. y Vallinder, T. (Eds.) (1995). The global expansion of judicial power. Nueva York, Estados Unidos: New York University Press

Uprimny, R. (2011). Las transformaciones constitucionales recientes en América Latina: tendencias y desafíos. En: C. Rodríguez Garavito (Coord.), El derecho en América Latina (pp.109-139). Buenos Aires, Argentina: Siglo XXI Editores.

Viciano, R. y Moreno, G. (2018). Cuando los jueces declaran inconstitucional la Constitución: la reelección presidencial en América Latina a la luz de las últimas decisiones de las Cortes constitucionales. Anuario Iberoamericano de Justicia Constitucional 22, pp. 165-198.

Wola (2017). Actualización sobre el caso de los 43 estudiantes desaparecidos en México. Wola. Recuperado de: https://www.wola.org/es/2017/09/actualizacionde-wola-sobre-el-caso-de-los-43-estudiantes-desaparecidos-en-mexicoseptiembre-de-2017/ 